Brit. J. prev. soc. Med. (1976), 30, 151-157

\title{
Cancer mortality and saccharin consumption in diabetics
}

\author{
BRUCE ARMSTRONG*1 A. J. LEA, $\dagger$ A. M. ADELSTEIN2, J. W. DONOVAN $\$ 2$, \\ G. C. WHITE 2 , S. RUTTLE 3
}

Department of the Regius Professor of Medicine, Oxford University 1 , the Office of Population Censuses and Surveys, London ${ }^{2}$, and the Defartment of Health and Social Security, London ${ }^{3}$

\begin{abstract}
Armstrong, B., Lea, A. J., Adelstein, A. M., Donovan, J. W., White, G. C., and Ruttle, S. (1976). British Journal of Preventive and Social Medicine, 30, 151-157. Cancer mortality and saccharin consumption in diabetics. The mortality experience of 5971 members of the British Diabetic Association (BDA) was followed-up for between five and eight years to mid-1973. Overall, 1207 deaths occurred compared with 778 expected from the mortality of the population of England and Wales in 1972. This excess of deaths was due almost entirely to diabetes mellitus and ischaemic heart disease. Deaths from cancer (128) were significantly fewer than expected (168), mainly because of a deficit in the number of deaths from cancers related to smoking (cancers of the buccal cavity and pharynx, oesophagus, respiratory system, and bladder). There was also a lower than expected mortality from chronic bronchitis and emphysema. Data on saccharin consumption by BDA members showed that more than half of them used saccharin tablets daily, with an overall daily intake of three to six tablets, depending on age and sex. Information on a small sample of survivors from the mortality study suggested that about $23 \%$ of them would have taken saccharin daily for 10 years or more and $10 \%$ for 25 years or more by the end of the follow-up. It was concluded that these relatively high levels of saccharin intake had not increased the risk of cancer in general among BDA members.
\end{abstract}

The subject of cancer mortality in diabetics has excited interest for some time and has been reviewed in detail by Kessler (1971). Recently, bladder cancer mortality has been studied in diabetics as an indirect means of determining whether the use of saccharin increases the risk of this cancer in man (Armstrong and Doll, 1975), but no such increase was shown. However, that study compared patients who died from cancer of the bladder with patients who died from other cancers (excluding cancers of the lung and pancreas), and thus it could not test whether Present address: Department of Medicine, University of Western
Australia
tDeceased
†Present address: Australian Department of Health, Canberra,
Australia saccharin increased the mortality from all cancers. We have therefore studied saccharin consumption by members of the British Diabetic Association (99\% of whom suffer from diabetes) in parallel with their mortality to obtain further information on the relationship between saccharin consumption, diabetes, and cancer.

\section{MethodS}

\section{CanCer Mortality}

A prospective study of mortality in diabetics was begun by one of us (AJL) in collaboration with the BDA and the Office of Population Censuses and Surveys (OPCS), then the General Register Office. 
From November 1965 until the end of 1968 the names, addresses, and dates of birth were obtained of new members and some old members of the BDA who were resident in England and Wales. These data were sent to the National Health Service Central Register (NHSCR) and, although the records of this part of the study are incomplete, it appears that about $95 \%$ of these individuals were identified in the register and had their records tagged. Since that time, as individuals have died, the OPCS has been notified and a copy of the death certificate placed in a special file. The present study deals only with those BDA members who were identified at NHSCR, and includes all notified deaths which occurred before 1 July 1973. Six months were allowed for late notifications before closing the file.

The sex and age distributions of the 5971 BDA members included in the study are summarized in Table I, together with the number of person years of experience contributed by each sex/age group. In calculating person years of experience, dates of entry and death were assumed to be distributed evenly throughout the years in which they occurred.

The expected numbers of deaths were derived from a $10 \%$ random sample of all deaths which occurred in England and Wales in 1972, coded for all conditions (up to a maximum of six) mentioned on the death certificate. This sample of 57783 deaths was assumed to have been derived from $10 \%$ of the population of England and Wales in 1972 (OPCS, 1974), and was used to estimate the expected deaths in the manner described in the Appendix.

\section{RESULTS}

Overall, 1207 deaths occurred in the BDA members compared with 778 expected. Observed and expected numbers of deaths within major categorieso of underlying cause are shown in Table II. The excesses of deaths from diabetes mellitus ando ischaemic heart disease account for almost all the overall excess. There was a deficit of deaths from $\overrightarrow{\vec{b}}$ malignant neoplasms (128 observed; 168 expected $P<0.01$ ).

Age-specific death rates for all types of cancer in male BDA members were used as reference rates top calculate age-standardized death rates from cance in each sex, for deaths occurring from one to six years after entry to the study (Table III). Although $\vec{p}$ the numbers of deaths within each year after registration were small, there is no evidence fromb this table that the overall deficit of deaths fromb cancer was due to a relatively lower death rate immediately after entry.

Diabetes mellitus was mentioned on $44.5 \%$ of thei cancer death certificates, compared with $62.0 \%$ on death certificates assigned to other causes (excluding diabetes itself).

Observed and expected numbers of deaths coted to various cancer sites are shown in Table IV. ATEOD shown are the ratios of observed to expected number (standardized mortality ratios, SMRs) where either number was equal to or greater than $4 \cdot 0$. There was a significant deficit in the number of deaths from the smoking-related cancers in both sexes (cancerssof the buccal cavity and pharynx, oesophagus, respicatory system, and bladder (Doll, 1972)) which accounts for almost all the overall deficit in cancer deaths. Of these only lung cancer showed a statistically significant deficit when considered alonळ (SMR in men $=0.48)$. There were four deaths from bladder cancer compared with 5.8 expected $(\mathrm{SMR}=0.70$ with $95 \%$ confidence limits 0.19 to 1·79).

TABLE I

AGE AND SEX DISTRIBUTIONS OF THE NUMBERS OF PERSONS, AND PERSON YEARS OF EXPERIENCE INCLUDEDÖ IN THE STUDY OF MORTALITY IN BDA MEMBERS

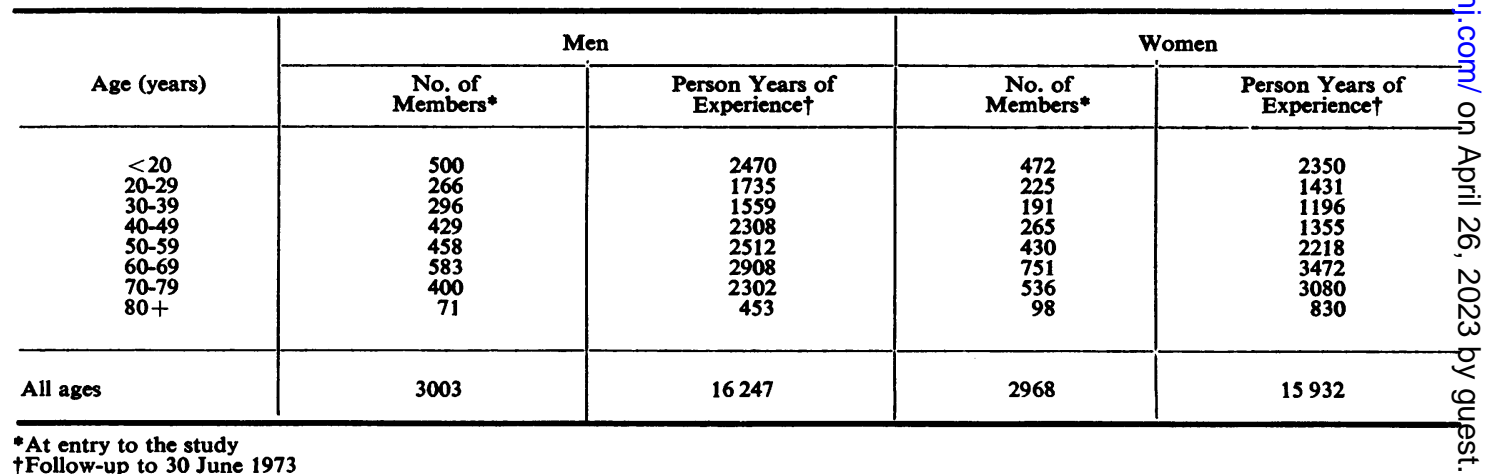


TABLE II

OBSERVED AND EXPECTED NUMBERS OF DEATHS ASSIGNED TO VARIOUS GROUPS OF DISEASES AS UNDERLYING CAUSE IN MALE AND FEMALE BDA MEMBERS

\begin{tabular}{|c|c|c|c|c|}
\hline ICD Rubrics & Group of Diseases & Observed & Expected & SMR* \\
\hline $\begin{array}{l}000-136 \\
140-209 \\
210-239 \\
250 \\
\text { Remainder of } \\
240-279 \\
280-289 \\
290-389 \\
410-414 \\
430-439 \\
\text { Remainder of } \\
390-458 \\
460-519 \\
520-577 \\
580-629 \\
-\end{array}$ & $\begin{array}{l}\text { Infective and parasitic diseases } \\
\text { Malignant neoplasms } \\
\text { Benign neoplasms } \\
\text { Diabetes mellitus } \\
\text { Other endocrine, nutritional, and metabolic disorders } \\
\text { Diseases of the blood and blood-forming organs } \\
\text { Mental and neurological disorders } \\
\text { Ischaemic heart disease } \\
\text { Cerebrovascular disease } \\
\text { Other diseases of the circulatory system } \\
\text { Diseases of the respiratory system } \\
\text { Diseases of the digestive system } \\
\text { Diseases of the genitourinary system } \\
\text { All other causes of death }\end{array}$ & $\begin{array}{r}7 \\
128 \\
4 \\
222 \\
8 \\
3 \\
1 \\
412 \\
131 \\
117 \\
111 \\
19 \\
15 \\
29\end{array}$ & $\begin{array}{r}3 \cdot 5 \\
168 \cdot 1 \\
1 \cdot 3 \\
7 \cdot 0 \\
2 \cdot 5 \\
2 \cdot 5 \\
9 \cdot 6 \\
215 \cdot 5 \\
110 \cdot 6 \\
94 \cdot 4 \\
112 \cdot 9 \\
20 \cdot 0 \\
11 \cdot 2 \\
29 \cdot 1\end{array}$ & $\begin{array}{c}2.02 \\
0.76 \ddagger \\
2.98 \\
31.76 \ddagger \\
3 \cdot 16 \ddagger \\
\\
0.10 \ddagger \\
1.91 \ddagger \\
1 \cdot 18 \\
1 \cdot 24 \dagger \\
0.98 \\
0.95 \\
1.34 \\
1.00\end{array}$ \\
\hline - & All causes of death & 1207 & $788 \cdot 3$ & $1 \cdot 53 \ddagger$ \\
\hline
\end{tabular}

- SMR (standardized mortality ratio) shown only where observed or expected number $\geqslant 4$ + Significance of difference from 1.0 (Bailar and Ederer, 1964): $P<0.05$

$\$ \mathrm{P}<0.01$

TABLB III

AGE-STANDARDIZED DEATH RATES FROM CANCER IN BDA MEMBERS ACCORDING TO THE TIME AFTER ENTRY AT WHICH THE DEATHS OCCURRED

\begin{tabular}{c|c|c|c|c}
\hline \multirow{2}{*}{$\begin{array}{c}\text { Years after } \\
\text { Registration }\end{array}$} & \multicolumn{2}{|c|}{ Men } & \multicolumn{2}{c}{ Women } \\
\cline { 2 - 5 } & $\begin{array}{c}\text { No. of } \\
\text { Deaths }\end{array}$ & $\begin{array}{c}\text { Death } \\
\text { Rate* }\end{array}$ & $\begin{array}{c}\text { No. of } \\
\text { Deaths }\end{array}$ & $\begin{array}{c}\text { Death } \\
\text { Rate* }\end{array}$ \\
\hline & 14 & 4.8 & 17 & 4.6 \\
2 & 14 & 4.9 & 7 & 1.9 \\
3 & 14 & 5.0 & 12 & 3.4 \\
4 & 10 & 1.8 & 8 & 2.3 \\
5 & 13 & 5.8 & 8 & 2.3 \\
$6+$ & 5 & 6 & 1.6 \\
\hline
\end{tabular}

- Rates are per 1000 person years at risk standardized indirect ly to the age distribution of cancer deaths in male BDA members
Table IV shows also there were significantly fewer deaths from rectal cancer, but an excess of deaths attributed to primary liver cancer. Both of these differences were common to the sexes. Two of the four patients who died from primary hepatoma had haemochromatosis mentioned on the death certificate. Also shown is an excess of cancer of the pancreas, but when the sexes are considered separately this is significant only for men (SMR in men $=2 \cdot 13$ ).

In view of the low mortality from smoking-related cancers, the mortality from respiratory diseases was also examined (Table V). Mortality from chronic bronchitis in male BDA members was significantly less than in the general population. There was also

TABLE IV

OBSERVED AND EXPECTED NUMBERS OF DEATHS IN BDA MEMBERS CODED TO VARIOUS CANCER SITES

\begin{tabular}{|c|c|c|c|c|c|c|c|c|c|c|}
\hline \multirow{2}{*}{ ICD Rubrics } & \multirow{2}{*}{ Cancer Site } & \multicolumn{3}{|c|}{ Underlying Cause Only } & \multicolumn{3}{|c|}{ All Mentions of Cancer Site } & \multicolumn{3}{|c|}{ Associated Cause } \\
\hline & & Observed & Expected & SMR* & Observed & Expected & SMR* & Observed & Expected & SMR* \\
\hline \multirow{4}{*}{$\begin{array}{l}154 \\
155 \\
157 \\
162 \\
188 \\
\text { Remainder of } \\
140-209\end{array}$} & $\begin{array}{l}\text { Rectum } \\
\text { Liver (primary) } \\
\text { Pancreas } \\
\text { Lung } \\
\text { Bladder }\end{array}$ & $\begin{array}{r}4 \\
4 \\
12 \\
22 \\
4\end{array}$ & $\begin{array}{r}8 \cdot 9 \\
0 \cdot 5 \\
8 \cdot 1 \\
47 \cdot 4 \\
5 \cdot 8\end{array}$ & $\begin{array}{l}0.45 \\
7.55 \ddagger \\
1.48 \\
0.46 \ddagger \\
0.70\end{array}$ & $\begin{array}{r}4 \\
4 \\
13 \\
24 \\
4\end{array}$ & $\begin{array}{r}10.4 \\
0.6 \\
8 \cdot 8 \\
50.1 \\
6.8\end{array}$ & $\begin{array}{l}0.38 t \\
6.45 \ddagger \\
1.47 \\
0.48 \ddagger \\
0.59\end{array}$ & $\begin{array}{l}\mathbf{0} \\
0 \\
1 \\
2 \\
0\end{array}$ & $\begin{array}{l}2 \cdot 1 \\
0 \cdot 2 \\
0.8 \\
3.9 \\
1.6\end{array}$ & $\begin{array}{l}= \\
\bar{z}\end{array}$ \\
\hline & Other sites & 82 & $97 \cdot 4$ & 0.84 & 173 & $200 \cdot 8$ & 0.86 & 29 & $27 \cdot 6$ & $1 \cdot 05$ \\
\hline & Cancers not & 30 & $61 \cdot 1$ & $0.49 \ddagger$ & 33 & $66 \cdot 2$ & $0.50 \ddagger$ & 3 & $7 \cdot 2$ & 0.42 \\
\hline & $\begin{array}{l}\text { smoking } \\
\text { All cancers }\end{array}$ & $\begin{array}{r}98 \\
128\end{array}$ & $\begin{array}{l}107 \cdot 0 \\
168 \cdot 1\end{array}$ & $\begin{array}{l}0.92 \\
0.76 \ddagger\end{array}$ & $\begin{array}{l}189 \\
222\end{array}$ & $\begin{array}{l}213 \cdot 3 \\
277 \cdot 5\end{array}$ & $\begin{array}{l}0.89 \\
0.80 \ddagger\end{array}$ & $\begin{array}{l}29 \\
32\end{array}$ & $\begin{array}{l}29 \cdot 0 \\
36 \cdot 2\end{array}$ & $\begin{array}{l}1.00 \\
0.88\end{array}$ \\
\hline
\end{tabular}

- SMR, shown only where observed or expected number $\geqslant 4$

$+\underset{\mathbf{P}<0.05}{\mathbf{P}<0.01}$

* Cancer of the buccal cavity and pharynx, oesophagus, respiratory system and bladder, ICD codes 140-149, 150, 160-163, 188 
TABLE V

OBSERVED AND EXPECTED NUMBERS OF DEATHS IN BDA MEMBERS CODED TO RESPIRATORY DISEASE

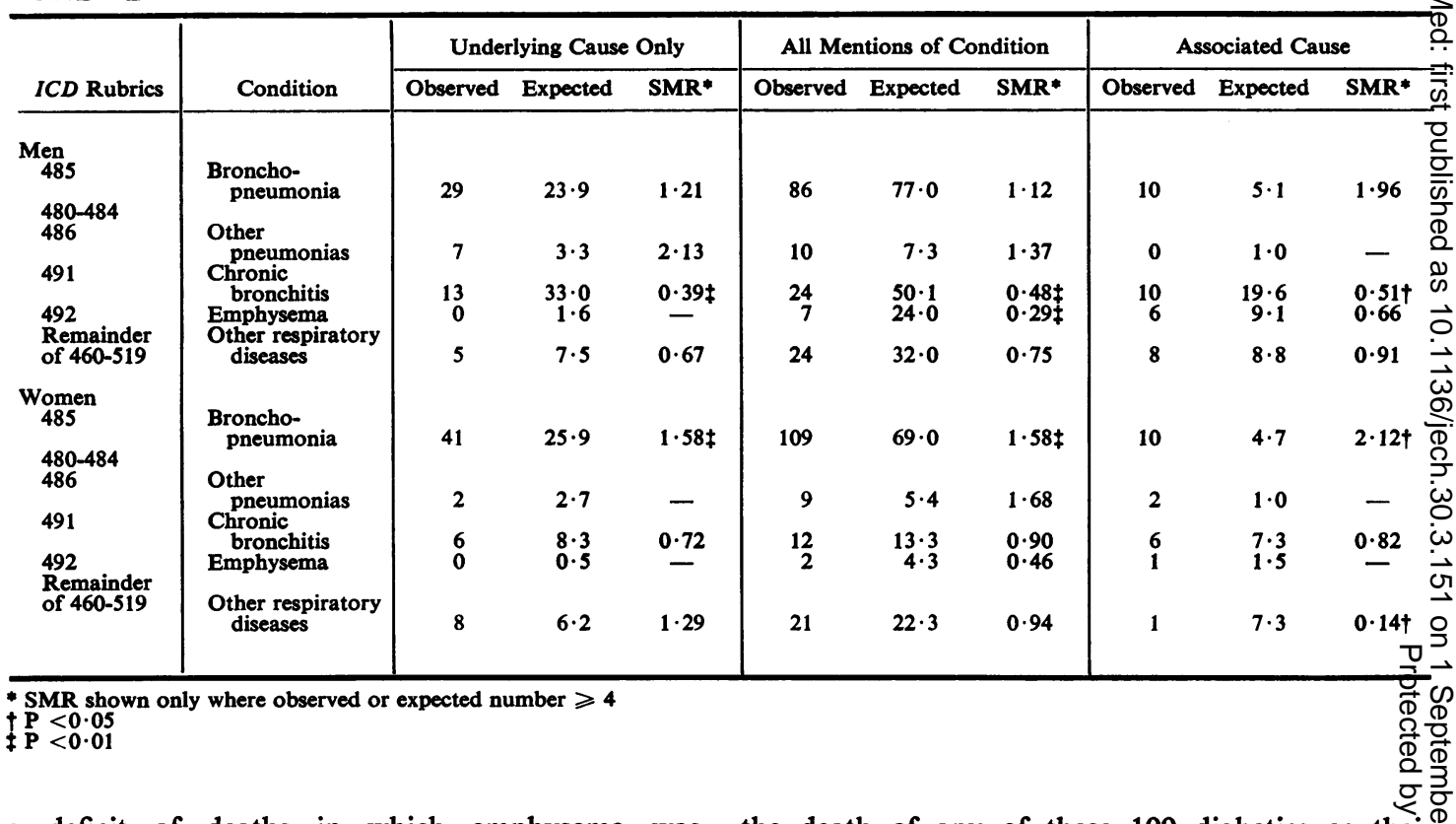

a deficit of deaths in which emphysema was mentioned as an associated cause. In contrast, there was a substantial excess of deaths with bronchopneumonia mentioned, particularly in women.

\section{SACCHARIN CONSUMPTION}

\section{MeTHODS}

In 1973 a questionnaire on artificial sweetener consumption was sent to a random sample of 4000 members of the BDA (approximately $10 \%$ of the total membership). Replies were received from 3096 members $(77 \cdot 4 \%)$, of whom 1600 were males, 1485 were females, and 11 did not indicate their sex. The males were aged between three and 93 years (average 50.7), and the females between two and 93 years (average 52.6).

In 1975 , a similar questionnaire, which included a question on the date of diagnosis of diabetes, was sent to a random sample of 100 members of the BDA who were included in the mortality study but who were known not to have died. The addresses of these people were about 10 years old and the response rate was expected to be fairly low; in fact replies were received from only 62 of these 100 diabetics. The remainder either could not be traced through the post office (11), had died recently (two), or did not respond to two letters (25). One of the responders indicated that she did not have diabetes. However, the low response rate is unlikely to be the result of the death of any of these 100 diabetics as their records at the NHSCR indicated that they were aluee and only very rarely will the NHSCR not be notifieds of a death and the record be marked accordingty Of the 61 diabetics who replied, 28 (45.9\%) were men aged between 19 and 94 years (average 48.7) and $33(54 \cdot 1 \%)$ were women aged between 13 an丸o 82 years (average $57 \cdot 8$ ).

\section{RESULTS}

Sample of All BDA Members

The daily use of saccharin tablets by the sample of all BDA members is shown in Table VI. AD substantially higher proportion of men than women? used saccharin tablets daily (age-standardized $\chi_{1}^{2}=$. 48.9, P $<0.001$; Mantel and Haenszel, 1959). There was significant heterogeneity by age in the pro portions of men and women using saccharin tablets daily (men, $\chi_{3}^{2}=47 \cdot 1, P<0.001$; women, $\chi_{3}^{2} \Rightarrow$ $36.5, P<0.001)$ and the trend towards a higher proportion of users with increasing age in men wass significant but non-linear $\left(\chi_{1}^{2}\right.$ for trend $=22 \cdot 7 \mathrm{~N}$ $P<0.001 ; \chi_{2}^{2}$ for departures from linear trend $=N$ $24.4, P<0.001$ ). The overall averages of $5 . \mathscr{F}$ saccharin tablets daily for men and 3.4 daily fof women are equivalent to $0.99 \mathrm{mg} / \mathrm{kg}$ per day an $0.65 \mathrm{mg} / \mathrm{kg}$ per day respectively, assuming the same 
TABLE VI

PERCENTAGES OF BDA MEMBERS USING SACCHARIN TABLETS DAILY, SUBDIVIDED BY SEX AND AGE

\begin{tabular}{|c|c|c|c|c|c|c|c|c|}
\hline \multirow{3}{*}{ Age (years) } & \multirow{3}{*}{ No. of Subjects* } & \multicolumn{7}{|c|}{ Daily Saccharin Tablet Consumption } \\
\hline & & \multicolumn{5}{|c|}{ Percentage Distribution } & \multicolumn{2}{|c|}{ Tablets Per Day } \\
\hline & & None & $1-4$ & $5-9$ & $10-19$ & $20+$ & Average & Range \\
\hline $\begin{array}{l}\text { Men } \\
<20 \\
20-39 \\
40-59 \\
60+ \\
\text { All ages }\end{array}$ & $\begin{array}{r}181 \\
250 \\
477 \\
646 \\
1554\end{array}$ & $\begin{array}{l}33 \cdot 7 \\
50 \cdot 0 \\
34 \cdot 4 \\
26 \cdot 0 \\
33 \cdot 3\end{array}$ & $\begin{array}{l}26 \cdot 5 \\
12 \cdot 4 \\
18 \cdot 0 \\
24 \cdot 4 \\
20 \cdot 8\end{array}$ & $\begin{array}{l}24 \cdot 3 \\
12 \cdot 0 \\
18 \cdot 4 \\
21 \cdot 8 \\
19 \cdot 5\end{array}$ & $\begin{array}{l}12 \cdot 7 \\
17 \cdot 2 \\
20 \cdot 5 \\
24 \cdot 1 \\
20 \cdot 6\end{array}$ & $\begin{array}{l}2.8 \\
8.4 \\
8.6 \\
3.6 \\
5.8\end{array}$ & $\begin{array}{l}4 \cdot 7 \\
5.4 \\
6 \cdot 4 \\
6 \cdot 0 \\
5.9\end{array}$ & $\begin{array}{l}0-68 \\
0-44 \\
0-50 \\
0-35 \\
0-68\end{array}$ \\
\hline $\begin{array}{c}\text { Women } \\
<20 \\
20-39 \\
40-59 \\
60+ \\
\text { All ages }\end{array}$ & $\begin{array}{r}172 \\
196 \\
356 \\
697 \\
1421\end{array}$ & $\begin{array}{l}36 \cdot 0 \\
61 \cdot 7 \\
48 \cdot 8 \\
40 \cdot 2 \\
44 \cdot 8\end{array}$ & $\begin{array}{l}33 \cdot 1 \\
19 \cdot 4 \\
21 \cdot 3 \\
28 \cdot 8 \\
26 \cdot 2\end{array}$ & $\begin{array}{l}19 \cdot 2 \\
11 \cdot 2 \\
16 \cdot 3 \\
19 \cdot 6 \\
17 \cdot 6\end{array}$ & $\begin{array}{r}10.5 \\
7.1 \\
12.1 \\
9.3 \\
9.8\end{array}$ & $\begin{array}{l}1.2 \\
0.5 \\
1.4 \\
2.0 \\
1.5\end{array}$ & $\begin{array}{l}3 \cdot 7 \\
2.3 \\
3.4 \\
3.7 \\
3.4\end{array}$ & $\begin{array}{l}0-30 \\
0-40 \\
0-21 \\
0-40 \\
0-40\end{array}$ \\
\hline
\end{tabular}

- 121 subjects not included because of incomplete data

mean body weights as were observed in diabetics in Oxford (Armstrong and Doll, 1975). These useage figures are similar to those observed in the Oxford diabetics (1.02 and $0.46 \mathrm{mg} / \mathrm{kg}$ per day), although the proportions of daily users were somewhat higher among the BDA members $(66 \cdot 7 \%$ and $55 \cdot 2 \%$ compared with $54 \cdot 1 \%$ and $33 \cdot 0 \%$ ).

The effect of duration of diabetes on the use of saccharin tablets is shown in Table VII. Indirect age-standardization was used with the overall percentages of saccharin-tablet users as standards. There were no pronounced trends, but the proportion of men taking saccharin tablets daily was significantly less in those with diabetes of 30 or more years' duration than in those who had recently become diabetic. This may have been due to the time of diagnosis of diabetes (before 1943 when saccharin use was less common (Armstrong and Doll, 1974)) rather than to a tendency to discontinue taking saccharin with a long duration of disease.

TABLE VII

EFFECT OF DURATION OF DIABETES ON THE AGE STANDARDIZED PERCENTAGE OF BDA MEMBERS USING SACCHARIN TABLETS DAILY

\begin{tabular}{c|c|c|c|c}
\hline \multirow{2}{*}{$\begin{array}{c}\text { Duration of } \\
\text { Diabetes (years) }\end{array}$} & \multicolumn{2}{|c|}{$\begin{array}{c}\text { Number of } \\
\text { Subjects* }\end{array}$} & \multicolumn{2}{|c}{$\begin{array}{c}\text { Percentage Using } \\
\text { Saccharin Tablets } \\
\text { Daily }\end{array}$} \\
\cline { 2 - 5 } & Men & Women & Men & Women \\
\hline $0-4$ & 539 & 475 & $70 \cdot 5$ & $53 \cdot 5$ \\
$5-9$ & 353 & 306 & $66 \cdot 1$ & $55 \cdot 2$ \\
$10-19$ & 384 & 408 & $65 \cdot 1$ & $57 \cdot 9$ \\
$20-29$ & 172 & 156 & $68 \cdot 3$ & $54 \cdot 9$ \\
$30+$ & 99 & 77 & $51 \cdot 4 \dagger$ & $51 \cdot 4$ \\
\hline
\end{tabular}

* 127 subjects not included because of incomplete data

tProportion of $30+$ years' duration diabetics significantly less than proportion of shorter duration diabetics; age-standardized $x_{1}^{2}=9.2, P<0.01$

\section{Sample of Survivors in the Mortality Study}

Table VIII shows the frequency of use of saccharin tablets distributed by duration of diabetes at entry in the sample of survivors in the mortality study. This suggests that about $23 \%$ (95\% confidence limits 13 to $36 \%$ ) of all diabetics had used saccharin tablets daily for five years or more before entry to the study, and about $10 \%(95 \%$ confidence limits 4 to $21 \%)$ for 20 years or more. Since the average period of follow-up in the mortality study was five years, by the end of follow-up about $23 \%$ of diabetics would have used saccharin tablets daily for 10 years or more.

\section{TABLE VIII}

DISTRIBUTION OF THE SAMPLE OF 61 DIABETIC SURVIVORS IN THE MORTALITY STUDY ACCORDING TO CURRENT (1975) USE OF SACCHARIN TABLETS AND DURATION OF DIABETES AT ENTRY TO THE STUDY

\begin{tabular}{|c|c|c|c|c|c|}
\hline \multirow{2}{*}{$\begin{array}{l}\text { Current Frequency of } \\
\text { Saccharin Tablet Use }\end{array}$} & \multicolumn{4}{|c|}{$\begin{array}{l}\text { Duration of Diabetes } \\
\text { at Entry to Mortality } \\
\text { Study (years) }\end{array}$} & \multirow{2}{*}{$\begin{array}{c}\text { All } \\
\text { Diabetics } \\
(\%)\end{array}$} \\
\hline & $<5$ & $5-9$ & $10-19$ & $20+$ & \\
\hline $\begin{array}{l}\text { Never } \\
\text { Less than once per day } \\
\text { Daily* } \\
\text { Dailyt } \\
\text { All diabetics (\%) }\end{array}$ & $\begin{array}{c}7 \\
7 \\
16 \\
1 \\
50 \cdot 8\end{array}$ & $\begin{array}{c}0 \\
4 \\
4 \\
1 \\
14 \cdot 8\end{array}$ & $\begin{array}{c}5 \\
1 \\
4 \\
1 \\
18 \cdot 0\end{array}$ & $\begin{array}{c}1 \\
2 \\
6 \\
1 \\
16 \cdot 4\end{array}$ & $\begin{array}{r}21 \cdot 3 \\
23 \cdot 0 \\
49 \cdot 2 \\
6 \cdot 5 \\
100\end{array}$ \\
\hline \multicolumn{6}{|c|}{$\begin{array}{l}\text { * Since within one year of diagnosis of diabetes } \\
\text { † Beginning more than one year after diagnosis of diabetes }\end{array}$} \\
\hline
\end{tabular}

Our results suggest that diabetics have a lower mortality from cancer than do members of the general population, mainly because there are fewer 
deaths from smoking-related cancers. Only cancer of the pancreas and primary liver cancer occurred significantly more frequently than expected in the BDA members.

The data on saccharin use by diabetics indicate high levels of consumption which were maintained throughout the course of the disease (Tables VI and VII). The data on saccharin consumption by survivors in the mortality study, although sparse and incomplete, suggest that as many as $10 \%$ may have used saccharin for 25 years or more by the end of follow-up, allowing time, perhaps, for a carcinogenic effect to become manifest.

The combination of heavy saccharin consumption and a relatively low mortality from cancer in BDA members suggests that saccharin does not generally increase the risk of cancer. It appears, therefore, that the use of patients with cancer (other than cancers of the lung and pancreas) as a control group in a previous study of the relationship of diabetes (and indirectly saccharin) to bladder cancer (Armstrong and Doll, 1975) was unbiased with respect to these exposures. There may, however, have been a small bias towards overestimation of the relative risk of bladder cancer because of the exclusion of lung cancer only rather than all smoking-related cancers from the control group.

With respect to the possible adverse effects of saccharin, it is also reassuring to note that this study showed no evidence of an increased risk of bladder cancer in diabetics, although from small numbers (four deaths observed, 5.8 expected; SMR 0.70 with $95 \%$ confidence limits $0 \cdot 19$ to $1 \cdot 79$ ).

Two sources of bias could explain the overall lower than expected mortality from cancer.

1. The inclusion of experience derived from early years of the study in which new members of the BDA may have been 'healthier' than diabetics in general.

2. The emigration of BDA members from England and Wales, as no allowance could be made for this in calculating the person years of experience.

It is unlikely that either of these sources of bias could explain the specific distribution of the deficit in cancer deaths to smoking-related sites. In any case, Table III shows no evidence of a lower rate in cancer deaths during the early years of the study, and it may be estimated from appropriate statistics (OPCS, 1971) that only about 17 persons a year would have emigrated from a population of the size, age, and sex structure of the original sample of BDA members.

The suggestion that the deficit of smoking-related cancers in diabetics may be due to a relatively low consumption of cigarettes (Armstrong and Doll, 1975) is supported by evidence of a low mortality from other respiratory diseases related to smoking@ (chronic bronchitis and emphysema, Table V). The $=$ degree of reduction in risk of lung cancer in diabeticsos observed in this study (about $50 \%$ ) is, however, substantially greater than that which it was estimatedo could be explained by the difference between the $\frac{\bar{s}}{5}$ proportions of smokers in diabetics and non- $-\frac{\pi}{\Omega}$ diabetics in Boston (12\%; Armstrong and Doll, 1975). This discrepancy is difficult to explain in the absence of adequate information on the smoking? habits of diabetics in the United Kingdom and the effect of smoking on the cardiovascular mortality of diabetics. It is possible, however, that selectived mortality of diabetic smokers from cardiovascular? disease might not only reduce the proportion of current smokers among diabetics, but remove also those smokers at highest risk of another smoking $\vec{r}$ related disease (by reason of amount smoked $\vec{\circ}$ method of smoking, etc.). Therefore, an estimatebased only on the reduction in the proportion $\Phi f_{0 S}$ current smokers might underestimate the to aldo reduction which might be expected in the incidenge of non-vascular diseases related to smoking. In the analysis of this study, use was made of allow conditions mentioned on the death certificate. This did not alter any positive conclusions which wotad have been made by studying the underlying causes only. It did, however, reveal that few deatho certificates for men mentioned emphysema, and showed a significant deficit in all mentions of rectal cancer. The second observation is based ono small numbers (four observed, 10.4 expected) and,, considering the many SMRs calculated, it could have occurred by chance. It is possible, however, in 3 view of the recent suggestion that rectal cancer may be associated with a high intake of beer (Breslow and Enstrom, 1974), that it may relate to the relatively low beer intake of diabetics (Armstrong, un-? published).

The encouragement and advice of Sir Richard Doll andồ Mr Richard Peto, and the clerical assistance of Mrs D. McClelland, are gratefully acknowledged. The study윽 was supported in part by a grant from the Department of Health and Social Security and Bruce Armstrong waso supported by a Clinical Sciences (Epidemiology) Fellowship of the National Health and Medical Research $N$ Council of Australia.

Requests for reprints: Dr A. M. Adelstein, Office of Population Censuses and Surveys, Medical Statisticso Division, St Catherine's House, 10 Kingsway, London WC2B 6JP. 


\section{REFERENCES}

Armstrong, B. and Doll, R. (1974). Bladder cancer mortality in England and Wales in relation to cigarette smoking and saccharin consumption. Brit. J. prev. soc. Med., 28, 233.

and - (1975). Bladder cancer mortality in diabetics in relation to saccharin consumption and smoking habits. Brit. J. prev. soc. Med., 29, 73.

BAILAR, J. C. and EDERER, F. (1964). Significance factors for the ratio of a Poisson variable to its expectation. Biometrics, 20, 639.

BREsLow, N. E. and ENSTROM, J. E. (1974). Geographic correlations between cancer mortality rates and alcohol-tobacco consumption in the United States. J. nat. Cancer Inst., 53, 631.

Doll, R. (1972). Cancers related to smoking. In The Second World Conference on Smoking and Health. edited by C. G. Richardson, p. 10. Pitman, London.

Kessler, J. I. (1971). Cancer and diabetics: a review of the literature. J. chron. Dis., 23, 579.

MaNTEL, N. and Haenszel, W. (1959). Statistical aspects of the analysis of data from retrospective studies of disease. J. nat. Cancer Inst., 22, 719.

Office of Population, ${ }^{7}$ Censuses and Surveys (1971). The Registrar General's Statistical Review of England and Wales for the Year 1969. Part II. Tables, Population. HMSO, London.

(1974). The Registrar General's Statistical Review of England and Wales for the Year 1972. Part II. Tables, Population. HMSO, London.

\section{APPENDIX}

The expected numbers of deaths were estimated for each three-digit rubric of the 8th revision of the International Classification of Diseases (ICD) in the following manner:

1. The expected number of deaths assigned to the rubric as underlying cause.
2. The expected number of deaths in which any condition mentioned on the death certificate was coded to the rubric.

3. The expected number of deaths in which an associated cause of death was coded to the rubric. For this analysis, all conditions mentioned after the underlying cause on the death certificate were considered to be associated causes of death.

The expected numbers of deaths in 1 and 2 above were calculated in the usual way they are estimated in prospective studies. That is, for $\boldsymbol{n}$ age-sex groups over which the expected numbers are to be standardized, the expected number is equal to

$$
\sum_{j=1}^{\mathrm{n}} \mathrm{S}_{j} \cdot \mathrm{Y}_{j} / \mathrm{X}_{j}
$$

where, in the ${ }_{j}$ 'th age-sex group, $S_{j}$ is the number of deaths coded to the rubric in the control population (counted as described in either 1 or 2 above) and $X_{j}$ and $Y_{j}$ are the numbers of person years of experience in the control and study populations respectively. In 3 above, the expected numbers are based on the prevalence at death of the associated causes. That is, the expected number is equal to

$$
\sum_{j=1}^{\mathbf{n}} \mathrm{S}_{j} \cdot \mathrm{T}_{j} / \mathrm{U}_{j}
$$

where $n, j$ and $S$, have the same meanings as before, and $T_{j}$ and $U_{j}$ are the total numbers of deaths in the $j$ 'th age-sex group of the study and control populations respectively. In each case, summation was performed over five-year age groups. 